\title{
A suplementação alimentar com ácidos graxos insaturados melhora a qualidade do sêmen criopreservado de búfalos (Bubalus bubalis) pós descongelação
}

\section{Dietary supplementation with unsaturated fatty acids improves quality of water buffalo (Bubalus bubalis) thawed semen}

\author{
Arnaldo Algaranhar Gonçalves ${ }^{1}$; Alexandre Rossetto Garcia ${ }^{2 *}$; \\ Rubens Paes de Arruda ${ }^{3}$; Waldomiro Barioni Junior ${ }^{2}$; \\ José de Brito Lourenço Junior ${ }^{4}$; Priscila Reis Kahwage ${ }^{1}$; Geanne Rocha da Silva ${ }^{1}$
}

\section{Resumo}

Este estudo investigou o efeito da inclusão de ácidos graxos insaturados (UFAs) na dieta sobre a qualidade do sêmen descongelado de bubalinos, além de verificar o grau de associação entre técnicas de avaliação da integridade de membrana plasmática (IMP) dos espermatozoides. Foram avaliados parâmetros de motilidade (subjetiva e computadorizada), cinética, morfologia espermática e IMP. A IMP foi avaliada pelos testes hiposmótico, coloração de eosina-nigrosina (E-N) e sondas fluorescentes (iodeto de propídio/Hoescht 33342; IP-H342). O experimento foi delineado para execução com dois grupos experimentais, avaliados em medidas repetidas ao longo do tempo. Onze touros bubalinos Murrah $(3,5 \pm 1,0$ anos e $536,9 \pm 73,0 \mathrm{~kg})$ foram divididos de modo inteiramente casualizado, em dois tratamentos: Grupo Controle (CONT, $n=5$ ) e Grupo Óleo de Palma (OP, $n=6)$. Os animais receberam forragem e concentrado de maneira controlada. $\mathrm{O}$ grupo $\mathrm{OP}$ recebeu óleo de palma adicionalmente na dieta ( $2 \%$ da matéria seca). O consumo foi diariamente controlado e o nível de ingestão de UFAs em OP foi 55,4\% superior ao CONT. As coletas seminais foram realizadas a cada 14 dias, durante 120 dias. As variáveis de qualidade do sêmen foram avaliadas em quatro períodos de tempo (Períodos I, II, III e IV), com intervalos de 30 dias cada. O nível de significância adotado foi de 5\%. Não houve efeito do tratamento sobre a motilidade espermática $(\mathrm{P}>0,05)$, mas a suplementação apresentou efeito positivo no Período IV $(\mathrm{P}<0,05)$, sobre a habilidade de progressão dos espermatozoides, conferida conjuntamente por BCF, STR e LIN. Alta correlação (91\%) foi observada entre as técnicas de IP$\mathrm{H} 342$ e $\mathrm{E}-\mathrm{N}\left(\mathrm{Y}=0,9155 \mathrm{x}+2,9843 ; \mathrm{R}^{2}=0,82 ; \mathrm{P} \leq 0,05\right)$. Assim, a suplementação com UFAs aumentou a capacidade de progressão das células espermáticas após 90 dias do início do tratamento, sem prejudicar as demais variáveis. A coloração com eosina-nigrosina pode ser utilizada eficientemente como preditora dos níveis de IMP, quando as condições para execução da técnica com sondas fluorescentes não estejam presentes.

Palavras-chave: Ácido graxo insaturado, búfalo doméstico, integridade de membrana plasmática, sêmen descongelado, suplementação

\footnotetext{
${ }^{1}$ Discentes, Universidade Federal do Pará, UFPA, Belém, PA. E-mail: algaranhar.vet@gmail.com; priscila.kahwage@hotmail. com; ge_rocha@yahoo.com.br

2 Pesquisadores, Embrapa Pecuária Sudeste, CPPSE, São Carlos, SP. E-mail: alexandre.garcia@embrapa.br; waldomiro.barioni@ embrapa.br

3 Prof., Universidade de São Paulo, USP, Pirassununga, SP. E-mail: arrudarp@usp.br

${ }^{4}$ Prof., Universidade do Estado do Pará, UEPA, Belém, PA. E-mail: joselourencojr@yahoo.com.br

* Autor para correspondência
} 


\begin{abstract}
This research aimed to evaluate the effect of inclusion unsaturated fatty acids (UFAs) in the buffalo diet, on the sperm quality after thawing. In parallel, it was verified the degree of association among techniques to assess plasma membrane integrity (PMI) of spermatozoa. Patterns of sperm motility (subjective and computer-assisted analysis), kinetics, morphology and plasma membrane integrity were evaluated. The hypo-osmotic swelling test, nigrosin-eosin staining (E-N) and fluorescent probes propidium iodide/Hoechst 33342 (IP-H342) were adopted to evaluate PMI. The study was planned considering two experimental groups, which were evaluated in repeated measures design. over time. Eleven Murrah buffalo bulls ( $3.5 \pm 1.0$ years, and $536.9 \pm 73.0 \mathrm{~kg}$ ) were divided in Control Group (CONT, $\mathrm{n}=5$ ) and Palm Oil Group (PO, $\mathrm{n}=6$ ). Animals were fed with forage and concentrated in a controlled manner. Animals of PO received dietary supplementation containing palm oil ( $2 \%$ of dry matter). Dietary consumption was daily monitored and the intake level of UFAs in PO was $55.4 \%$ higher than CONT. Semen samples were collected and evaluated every 14 days. The experiment lasted 120 days, considering four periods of 30 days each (Periods I, II, III and IV) and repeated measures structure was used in statistical analysis. Significance level adopted was 5\%. There was no effect of treatment on sperm motility $(\mathrm{P}>0.05)$, but palm oil supplementation presented a positive effect on spermatic ability to progress (derived from BCF, STR and LIN) in Period IV $(\mathrm{P}<0.05)$. High correlation $(91 \%)$ was observed between IP-H342 and E-N techniques $\left(\mathrm{Y}=0.9155 \mathrm{x}+2.9843, \mathrm{R}^{2}=0.82, \mathrm{P} \leq 0.05\right)$. Thus, supplementation with UFAs increased the progressivity of spermatozoa after 90 days, and had no effect on other seminal parameters. Eosin-nigrosin stain can be used efficiently as a predictor of the level of PMI when conditions for implementing fluorescent probes not present.
\end{abstract}

Key words: Plasma membrane integrity, supplementation, thawed semen, unsaturated fatty acids, water buffalo

\section{Introdução}

A população mundial de búfalos (Bubalus bubalis) cresce a cada década e, atualmente, é de 168 milhões de cabeças, sendo que o continente asiático concentra mais de $95 \%$ dessa população. Além de ser usado como animal de tração em diversos países, a espécie apresenta relevante papel na produção de carne e leite (LOURENÇO JÚNIOR; GARCIA, 2006), com crescente interesse pelos derivados lácteos no mercado internacional (BORGHESE; MAZZI, 2005). Para ser mais competitiva, a bubalinocultura deve elevar o padrão genético dos animais, o que pode ser facilitado pela ampliação de novos programas de inseminação artificial e consolidação dos já existentes (ANDRABI, 2009).

Em geral, os programas de inseminação artificial em bubalinos são executados tendo como base o uso do sêmen congelado (GARCIA et al., 2008). Contudo, tanto no bubalino como em outras espécies, o processo de criopreservação causa inúmeras injúrias nas células espermáticas, as quais ocasionam decréscimo ou perda da capacidade de fertilização (SANSONE; NASTRI; FABBROCINI, 2000). As etapas da criopreservação, assim como a descongelação do sêmen, geram modificações na composição lipídica da membrana plasmática do espermatozoide, por desestabilizar a bicamada lipídica (WATSON, 2000; KUMAR; ATREJA, 2012). Outros efeitos perceptíveis são a indução da capacitação espermática precoce e a diminuição do tempo de vida útil dos espermatozoides (RASUL; AHMAD; ANZAR, 2001).

Em virtude da importância da participação dos lipídios na estrutura das células espermáticas, principalmente quando submetidas ao choque térmico pela criopreservação ou descongelação, estudos sobre a inclusão de lipídios na dieta de suínos (CASTELLANO et al., 2010; KAEOKET et al., 2010; AM-IN et al., 2011), ovinos (GRAAF et al., 2007; SELVARAJU et al., 2012), bovinos (GHOLAMI et al., 2011) e bubalinos (ADEEL et al., 2009) têm sido realizados, sendo os óleos de origem vegetal, como o de linhaça, soja, girassol e milho os mais comumente empregados na alimentação dos ruminantes.

Uma fonte de ácidos graxos insaturados (UFAs) é o óleo de palma, principal produto extraído do fruto da palmeira de dendê (Elaeis guineensis Jacq.) e que 
possui, entre outros lipídeos, o ácido linoleico ( $\omega-6)$ em sua composição (NORHAIZAN et al., 2013). No metabolismo animal, os UFAs são importantes no processo reprodutivo, especificamente na produção de esteroides (WANG et al., 2003), para a fluidez nas membranas plasmáticas do espermatozoide e oócito, nas mudanças no padrão de receptores de ligação (WATHES; ABAYASEKARA; AITKEN, 2007), como fonte de energia durante a maturação dos oócitos e no desenvolvimento embrionário após a implantação (FERGUSON; LEESE, 2006).

O principal ácido graxo encontrado nos espermatozoides é o ácido linolênico ( $\omega$-3), sendo que o ácido docosahexaenoico (DHA), um derivado $\omega-3$, tem importante papel na manutenção da integridade da membrana plasmática e na motilidade espermática, bem como confere maior criorresistência às células (ROBINSON et al., 2006). A presença de ácidos graxos insaturados na membrana plasmática ou no plasma seminal, principalmente da família dos $\omega-3$, influencia no metabolismo das células espermáticas (LENZI et al., 1996). Outras famílias de ácidos graxos, $\omega-6$ e $\omega-9$, participam na síntese das prostaglandinas ( $\mathrm{PGE}_{1}$, $\mathrm{PGE}_{1 \alpha}, \mathrm{PGE}_{2}$ e $\mathrm{PGE}_{2 \alpha}$ ) e seus precursores (ácido araquidônico e dihomo-gama-ácido linoleico) (WATHES; ABAYASEKARA; AITKEN, 2007).

$\mathrm{Na}$ avaliação andrológica, é importante considerar os danos irreversíveis impostos aos espermatozoides pela criopreservação, utilizando vários testes para avaliar o potencial fertilizante do espermatozoide (HOLT, 2000; ARRUDA et al., 2005). Normalmente, as avaliações mais rotineiras realizadas para determinar a qualidade seminal englobam os testes de motilidade e morfologia espermática (MAZIERO et al., 2009), além de técnicas para avaliar a integridade e função da membrana plasmática do espermatozoide, como o teste de eosina-nigrosina e o teste hiposmótico (BARROS et al., 2007; SELVARAJU; GHOSH; RAVINDRA, 2009). De forma complementar, técnicas mais elaboradas foram desenvolvidas mais recentemente para aumentar o grau de precisão das avaliações andrológicas, como a análise computadorizada da motilidade espermática (CASA - Computer Assisted Sperm Analisys) (CONTRI et al., 2010; CONTRI et al., 2013; HUSSAIN; LESSARD; ANZAR, 2013) e as técnicas baseadas no uso de sondas fluorescentes (CELEGHINI et al., 2007; KOONJAENAK et al., 2007).

A análise computadorizada da motilidade espermática (CASA) calcula de forma objetiva a motilidade e os parâmetros de movimentação do sêmen, proporcionando maior acurácia à avaliação (VERSTEGEN; IGUER-OUADA; ONCLIN, 2002; MORTIMER, 2000; COX et al., 2006). Esta ferramenta não somente pode ser utilizada para diminuir ou retirar a subjetividade do método convencional de avaliação da motilidade, mas também para investigar a cinética detalhada dos espermatozoides (MANDAL; BAGPAUL; GUPTA, 2003). Poucos estudos foram realizados com sêmen bubalino com o propósito de avaliar o comportamento da cinética espermática após os processos de congelação e descongelação (RASUL; AHMAD; ANZAR, 2000; RASUL; AHMAD; ANZAR, 2007; KOONJAENAK et al., 2007; ANIL KUMAR et al., 2011).

Já os testes com fluorocromos utilizam as sondas fluorescentes, as quais se ligam a moléculas específicas presentes na célula, a fim de avaliar a integridade e a função de compartimentos específicos dos espermatozoides (YÁNIZ et al., 2012). Corantes supravitais, como o iodeto de propídio e o Hoescht 33342, são usados para determinar a integridade de membrana plasmática, e se ligam de forma especifica ao DNA ao marcar o núcleo da célula em vermelho (lesada) e azul (não lesada), respectivamente (CELEGHINI et al., 2007). Porém, está técnica possui algumas desvantagens, como o alto investimento para a implantação do equipamento de microscopia de epifluorescência, além de toda estrutura física necessária para dar suporte a essa técnica. Ainda, a leitura após o preparo das amostras deve ser quase que imediata, a fim de evitar a perda das propriedades dos fluorocromos. 
Por isso, o primeiro objetivo deste estudo foi avaliar o efeito dos ácidos graxos insaturados, por meio da adição do óleo de palma na dieta, sobre os parâmetros de motilidade espermática subjetiva e automatizada, de cinética espermática, normalidade da morfologia dos espermatozoides e integridade de membrana espermática no sêmen bubalino criopreservado. Adicionalmente, verificou-se o grau de associação entre as técnicas de avaliação da integridade de membrana plasmática dos espermatozoides.

\section{Material e Métodos}

\section{Animais e local}

Onze touros bubalinos adultos da raça Murrah $(3,5 \pm 1,0$ anos e $536,9 \pm 73,0 \mathrm{~kg})$ foram utilizados como doadores de sêmen. Os animais foram mantidos em baias cobertas, sob condições ambientais uniformes. $O$ ensaio foi realizado na Embrapa Amazônia Oriental (Belém-PA, Brasil) e no Laboratório de Biotecnologia do Sêmen e Andrologia da FMVZ/USP (PirassunungaSP, Brasil), sendo que todos os procedimentos experimentais foram previamente aprovados pelo Comitê Técnico Interno da Embrapa Amazônia
Oriental, empresa vinculada ao Ministério de Agricultura Pecuária e Abastecimento do Brasil.

\section{Alimentação e manejo}

Os animais foram divididos em dois grupos: Grupo Controle (CONT; $n=5$ ) e o Grupo Tratado (OP; $\mathrm{n}=6$ ). Os touros de ambos os grupos receberam dieta isoproteica $(12,3 \%$ de proteína bruta) composta de volumoso de silagem de milho $(50 \%)$ e concentrado feito de farelo de trigo (CONT: 19,90\% e OP: 19,25\%), milho triturado (CONT: $29,5 \%$ e OP: $28,0 \%$ ) mais ureia (CONT: 0,6\% e OP: $0,7 \%$ ), formuladas de acordo com as exigências da categoria (PAUL; LAL, 2010). Para os animais do grupo tratado, houve a adição dos ácidos graxos insaturados por meio da mistura do óleo de palma no concentrado, referente a $2 \%$ da dieta, com base na matéria seca, o que distinguiu a composição bromatológica das dietas (Tabela 1). O perfil de ácidos graxos das dietas experimentais foi determinado por cromatografia gasosa dos ésteres metílicos de ácidos graxos e ionização de chama (CP 3380, equipado com CP-Sil 88 de $60 \mathrm{~m}$ x 0,25 mm, Varian Analytical Instruments, Walnut Creek, EUA). Cada amostra foi analisada em triplicata (RODRIGUES; DARNET; SILVA, 2010).

Tabela 1. Composição bromatológica das dietas enriquecidas (OP) ou não (CONT) com óleo de palma a 2\% da matéria seca, fornecidas a touros bubalinos em regime regular de colheita e congelação de sêmen.

\begin{tabular}{ccc}
\hline COMPOSIÇÃO & GONT & OPUPOS \\
\hline PB (\%) & 12,37 & 12,33 \\
EE (\%) & 3,47 & 5,43 \\
FDN (\%) & 32,12 & 31,51 \\
FDA (\%) & 23,95 & 23,59 \\
MS (\%) & 61,04 & 59,13 \\
\hline
\end{tabular}

*PB: Proteína Bruta; EE: Extrato Etéreo; FDN: Fibra em Detergente Neutro; FDA: Fibra em Detergente Ácido; MS: Matéria Seca. CONT: concentrado controle; OP: concentrado enriquecido com óleo de palma ( $2 \% \mathrm{MS})$.

Fonte: Elaboração dos autores. 
Durante 16 dias, antes do início do experimento, foi feita adaptação dos animais ao regime de manejo estabulado e à alimentação de volumoso e concentrado. O arraçoamento experimental durou 120 dias, sendo os animais alimentados duas vezes ao dia e monitorados quanto ao consumo diário para ajuste na quantidade a ser ofertada. Considerou-se o dia do arraçoamento experimental como dia zero (D0). Nas baias em que os animais foram confinados havia água em bebedouro automático e sal mineral ad libitum. O consumo médio diário de ácidos graxos insaturados no grupo CONT foi de 308,75 $\mathrm{g} /$ animal/dia e no grupo OP foi de 479,97 g/animal/ dia, o que garantiu um incremento na ingesta de ácidos graxos insaturados da ordem de 55,4\% nos animais tratados.

Coleta, criopreservação e descongelação do sêmen

O sêmen foi coletado por meio de vagina artificial a $42^{\circ} \mathrm{C}$, adaptada para espécie bubalina (VALE et al., 1984). Os touros tiveram ejaculados colhidos, em média, em intervalo de 14 dias, totalizando 100 ejaculados analisados. Previamente à coleta, os touros foram contidos e devidamente higienizados, sendo realizada uma falsa monta para estimulação sexual prévia. O sêmen in natura passou por análise de rotina para as características físicas e morfológicas (VALE et al., 1984) e apresentou médias para volume de $3,7 \pm 1,2$ e $3,6 \pm 1,7 \mathrm{~mL}, \mathrm{pH}$ de $6,2 \pm 0,4$ e $6,3 \pm 0,3$, turbilhonamento de $2,8 \pm 0,5$ e $2,3 \pm 0,8$, vigor de $3,1 \pm 0,4$ e $3,0 \pm 0,3$, motilidade progressiva de $59,1 \pm 16,0 \%$ e $54,7 \pm 11,4 \%$, defeitos totais $20,4 \pm 9,6 \%$ e $19,2 \pm 7,4 \%$, e integridade de membrana plasmática (eosina-nigrosina) de $68,1 \pm 10,6 \%$ e $61,7 \pm 16,7 \%$, para os grupos CONT e $\mathrm{OP}$, respectivamente.

O sêmen foi diluído e criopreservado com diluidor TES-TRIS (VALE, 2002), em palhetas plásticas $\left(30 \times 10^{6} \mathrm{sptz}\right)$. O processo de criopreservação foi executado de modo automatizado em sistema programável (TK-3000, TK Equipamentos, Uberaba, Brasil), com curva de refrigeração e congelação controladas (CASTRO, 2010). Após a congelação, as palhetas foram submersas em nitrogênio liquido e estocadas a $-196^{\circ} \mathrm{C}$ por no mínimo um mês antes do início das análises. Para as avaliações, duas palhetas de cada ejaculado foram descongeladas em banho-maria a $37^{\circ} \mathrm{C}$ durante 30 segundos (KUMAR et al., 1993). O sêmen foi então colocado em um único microtubo e homogeneizado, sendo mantido sob temperatura controlada de $37^{\circ} \mathrm{C}$ durante todas as análises. As análises foram realizadas pelo mesmo observador, previamente treinado, para evitar variações.

\section{Avaliação da motilidade subjetiva}

Primeiramente, foram realizadas as análises de motilidade total (MOT-ST) e progressiva subjetiva (MOT-SP), em alíquota de $10 \mu \mathrm{L}$ de sêmen em lâmina pré-aquecida a $37^{\circ} \mathrm{C}$, analisada em microscópio óptico (Eclipse E200, Nikon, Japão) com aumento de 100x. O resultado foi expresso em porcentagem de células móveis.

Avaliação computadorizada da motilidade $e$ parâmetros de cinética espermática (CASA Computer Assisted Sperm Analysis)

Para realizar a análise espermática computadorizada (CASA), as amostras foram depositadas em câmara de Makler Counting Chamber (Sefi Medical Instruments, Haifa, Israel). Uma alíquota de $10 \mu \mathrm{L}$ da amostra foi depositada no centro da câmara e foram avaliados 10 campos distintos e aleatórios para cada amostra em equipamento HTM-IVOS, versão 12.3 (Hamilton Thorne Biosciences, Beverly, Massachusetts, USA). O set up do equipamento para análise do sêmen foi pré-ajustado com os seguintes parâmetros: número de frames captados: 60; frames por segundo: 60 Hz; contraste mínimo: 60; tamanho mínimo da célula: 6 pixels; VAP (path velocity): $38,0 \mu \mathrm{m} / \mathrm{s}$; STR (straightness): 60,0\%; VAP cutoff: 30,0 $\mu \mathrm{m} / \mathrm{s}$; VSL cutoff: $20,0 \mu \mathrm{m} / \mathrm{s}$; tamanho da célula: 
6 pixels; intensidade da célula: 80; magnificação: 1,89; frequência de vídeo: $60 \mathrm{~Hz}$; intensidade de iluminação: 2150 ; temperatura: $37^{\circ} \mathrm{C}$. As seguintes variáveis de movimento das células espermáticas foram avaliadas: motilidade total (MOT-T, \%) e motilidade progressiva (MOT-P, \%); velocidade média do trajeto (VAP, $\mu \mathrm{m} / \mathrm{s}$ ); velocidade curvilinear (VCL, $\mu \mathrm{m} / \mathrm{s}$ ); velocidade linear progressiva (VSL, $\mu \mathrm{m} / \mathrm{s})$; amplitude de deslocamento lateral da cabeça $(\mathrm{ALH}, \mu \mathrm{m})$; frequência de batimento flagelar cruzado (BCF, Hz); retilinearidade (STR, \%) e linearidade (LIN, \%) (CONTRI et al., 2010).

\section{Avaliação da morfologia espermática}

Os espermatozoides foram avaliados individualmente segundo tipo e grau de anormalidade presente. Alíquotas de $100 \mu \mathrm{L}$ de sêmen descongelado foram diluídas em $900 \mu \mathrm{L}$ de formalina tamponada para cada amostra. Uma gota de $10 \mu \mathrm{L}$ foi avaliada em microscópio de contraste de fase (Eclipse E200, Nikon, Japão), com aumento de 1000x. Foram contados 200 espermatozoides por amostra e classificados em defeitos maiores (DEFMA), defeitos menores (DEF-ME) e defeitos totais (DEF-T) (BLOM, 1973).

\section{Avaliação da integridade da membrana plasmática com sondas fluorescentes}

A integridade da membrana plasmática dos espermatozoides foi avaliada com uso de sondas fluorescentes (associação de iodeto de propídio/ Hoescht 33342), por teste hiposmótico e pela coloração de eosina-nigrosina, conforme descrito a seguir.

Em um microtubo aquecido a $37^{\circ} \mathrm{C}$, foram adicionados $150 \mu \mathrm{L}$ de sêmen descongelado em $150 \mu \mathrm{L}$ meio TALP, numa concentração final de $25 \mathrm{x}$ $10^{6}$ espermatozoides $/ \mathrm{mL}$. Em seguida, foi realizada adição de $3 \mu \mathrm{L}$ de iodeto de propídio (P4170 - Sigma - Aldrich) a $0,5 \mathrm{mg} / \mathrm{mL}$ e $2 \mu \mathrm{L}$ de Hoescht 33342 (H-1399 - Molecular Probes) a $5 \mathrm{mg} / \mathrm{mL}$, incubada a $37^{\circ} \mathrm{C}$ por 8 minutos em ambiente escuro, sendo analisado entre lâmina e lamínula pré-aquecidas a $37^{\circ} \mathrm{C}$, sob microscopia de epifluorescência (Nikon, Eclipse 80i, Melville, USA) com aumento de 1000x. Duzentas células foram contadas e classificadas de acordo com a fluorescência emitida: células consideradas com membrana plasmática lesada apresentavam fluorescência vermelha decorrente da ação do iodeto de propídio; células consideradas com membrana plasmática íntegra apresentavam fluorescência azul, coradas apenas pelo Hoescht 33342. O resultado foi dado em porcentagem de células com membrana plasmática íntegra (CELEGHINI et al., 2007).

Avaliação da integridade da membrana plasmática com teste hiposmótico (HOST)

Em microtubo, uma alíquota de $50 \mu \mathrm{L}$ de sêmen descongelado foi adicionada a $500 \mu \mathrm{L}$ de solução hiposmótica $(0,735 \mathrm{~g}$ de citrato de sódio, $1,351 \mathrm{~g}$ de frutose, $100 \mathrm{~mL}$ de água Milli-Q; $190 \mathrm{mOsm} \mathrm{kg}{ }^{-1}$ ) pré-aquecida a $37^{\circ} \mathrm{C}$. A amostra foi então incubada por 30 minutos. Em seguida foram adicionados 250 $\mu \mathrm{L}$ de formalina tamponada a $10 \%$ para fixação das células e análise posterior. Para análise, já utilizada uma gota de $10 \mu \mathrm{L}$ de cada amostra entre lâmina e lamínula, sendo visualizadas em microscópio de contraste de fase (Eclipse E200, Nikon, Japão), com aumento de 400x (RASUL; AHMAD; ANZAR, 2000). Duzentas células foram contadas, sendo que as células que apresentaram cauda enrolada ou dobrada foram classificadas como tendo membrana plasmática íntegra, descontados os valores de células com caudas dobradas ou enroladas mensurados após a descongelação e previamente à execução do teste hiposmótico (MELO; HENRY, 1999).

Avaliação da integridade da membrana plasmática com eosina-nigrosina

Uma alíquota de $8 \mu \mathrm{L}$ de sêmen descongelado foi depositada sobre lâmina pré-aquecida a $37^{\circ} \mathrm{C}$ e gentilmente misturada a $10 \mu \mathrm{L}$ de eosina-nigrosina ( $1 \%$ de eosina $\mathrm{B}, 5 \%$ de nigrosina e $3 \%$ de citrato 
de sódio) e homogeneizada (KHAN; IJAZ, 2008). Em seguida, foi realizado o esfregaço, com tempo de secagem de 2 minutos. A contagem diferencial considerou 200 células, que foram classificadas em duas categorias: células espermáticas não coradas, consideradas como tendo membrana plasmática íntegra, e células coradas parcial ou totalmente, consideradas como tendo membrana plasmática lesada (BRITO et al., 2003), utilizandose microscópio óptico (Eclipse E200, Nikon, Japão) com aumento de 1000x.

\section{Análise estatística}

O delineamento experimental adotado foi inteiramente casualizado, com dois tratamentos: Grupo Controle (CONT; $n=5$ ) e o Grupo Tratado (OP; n=6), numa estrutura de medidas repetidas no tempo. As variáveis de qualidade do sêmen, de cada animal, foram avaliadas em quatro períodos de tempo (Períodos I, II, III e IV), com intervalos de 30 dias cada. Os dados do experimento foram submetidos à análise de variância usando o procedimento Mixed do programa SAS (SAS Institut, Realese 9.1, Cary, NC, EUA, 2002/2003). Considerou-se nesta análise, o período como medida repetida. $\mathrm{Na}$ escolha das estruturas das matrizes de variância e covariâncias adotou-se o critério de informação Akaike (FREITAS; SOUZA; MOREIRA, 2011). Para as variáveis mensuradas em porcentagem, procedeu-se a transformação arco seno da raiz quadrada da proporção. Utilizou-se a análise de correlação e de regressão $(\mathrm{Y}=\mathrm{a}+\mathrm{bX})$ para avaliar o grau de relação linear entre as técnicas de avaliação da integridade de membrana plasmática dos espermatozoides (sondas fluorescentes, teste hiposmótico e eosina-nigrosina). Os dados foram apresentados em forma de tabelas e gráficos. Adotou-se o teste de Tukey na comparação múltipla de médias. Tanto para análise de variância como de regressão, o nível de significância usado foi $\mathrm{P} \leq 0,05$.

\section{Resultados}

Motilidade e parâmetros de cinética espermática

Foi observado o comportamento das variáveis de movimento espermático para sêmen descongelado, analisada de forma subjetiva e computadorizada, nos dois grupos e nos quatro diferentes períodos, além da interação entre grupos e períodos (Tabela 2).

Tabela 2. Média de mínimos quadrados \pm erro padrão da motilidade total e progressiva do sêmen bubalino descongelado, avaliada em microscopia óptica e em sistema computadorizado (CASA).

\begin{tabular}{|c|c|c|c|c|c|}
\hline & & & do & & \\
\hline Variável & $\begin{array}{c}\mathrm{I} \\
\text { (D0-D30) }\end{array}$ & $\begin{array}{c}\text { II } \\
\text { (D31-D60) }\end{array}$ & $\begin{array}{c}\text { III } \\
\text { (D61-D90) }\end{array}$ & $\begin{array}{c}\text { IV } \\
\text { (D91-D120) }\end{array}$ & Média Total \\
\hline MOT-ST (\%) & & & & & \\
\hline CONT & $40,3 \pm 5,4$ & $51,5 \pm 6,3$ & $47,1 \pm 6,3$ & $46,1 \pm 2,0$ & $46,3 \pm 3,3$ \\
\hline $\mathrm{OP}$ & $48,3 \pm 4,9$ & $48,3 \pm 6,8$ & $33,5 \pm 6,2$ & $51,4 \pm 1,9$ & $45,4 \pm 3,2$ \\
\hline MOT-SP (\%) & & & & & \\
\hline CONT & $34,0 \pm 6,0$ & $40,5 \pm 5,4$ & $35,2 \pm 5,4$ & $37,8 \pm 5,4$ & $36,9 \pm 2,7$ \\
\hline OP & $42,9 \pm 5,4$ & $39,1 \pm 6,0$ & $23,2 \pm 5,4$ & $36,7 \pm 5,4$ & $35,5 \pm 2,7$ \\
\hline MOT-T (\%) & & & & & \\
\hline CONT & $59,1 \pm 6,6$ & $68,7 \pm 6,1$ & $73,0 \pm 6,1$ & $59,4 \pm 6,1$ & $65,1 \pm 4,7$ \\
\hline $\mathrm{OP}$ & $62,2 \pm 6,0$ & $65,5 \pm 6,6$ & $57,4 \pm 6,0$ & $66,1 \pm 6,0$ & $62,8 \pm 4,5$ \\
\hline MOT-P (\%) & & & & & \\
\hline CONT & $54,7 \pm 6,5$ & $64,8 \pm 6,1$ & $67,7 \pm 6,1$ & $55,8 \pm 6,1$ & $60,7 \pm 4,7$ \\
\hline OP & $57,0 \pm 5,9$ & $59,7 \pm 6,5$ & $52,3 \pm 5,9$ & $60,6 \pm 5,9$ & $57,4 \pm 4,5$ \\
\hline
\end{tabular}

CONT: grupo controle; OP: grupo suplementado com óleo de palma (2\%MS); MOT-ST: motilidade subjetiva total; MOT-SP: motilidade subjetiva progressiva; MOT-T: motilidade total no CASA; MOT-P: motilidade total CASA. P>0,05.

Fonte: Elaboração dos autores. 
Não houve diferença significativa nas médias de motilidade total e progressiva em função do tratamento dietético, tanto na análise subjetiva quanto na computadorizada $(\mathrm{P}>0,05)$. Discretas diferenças numéricas, com valores superiores nas médias totais para o grupo CONT, foram notadas na motilidade total e progressiva. Os parâmetros de cinética espermática também foram investigados (Tabela 3).

Tabela 3. Média de mínimos quadrados \pm erro padrão dos parâmetros de cinética espermática (média $\pm \mathrm{DP})$ em sêmen bubalino descongelado, avaliado em sistema computadorizado (CASA).

\begin{tabular}{|c|c|c|c|c|c|}
\hline \multicolumn{6}{|c|}{ Período } \\
\hline Variável & $\begin{array}{c}\mathrm{I} \\
\text { (D0-D30) }\end{array}$ & $\begin{array}{c}\text { II } \\
\text { (D31-D60) }\end{array}$ & $\begin{array}{c}\text { III } \\
\text { (D61-D90) }\end{array}$ & $\begin{array}{c}\text { IV } \\
\text { (D91-D120) }\end{array}$ & Média Total \\
\hline \multicolumn{6}{|c|}{$\operatorname{VAP}(\mu \mathrm{m} / \mathrm{s})$} \\
\hline CONT & $86,5 \pm 4,1$ & $94,3 \pm 7,4$ & $98,6 \pm 6,2$ & $92,5 \pm 4,6$ & $93,0 \pm 4,7$ \\
\hline OP & $92,6 \pm 3,7$ & $88,5 \pm 7,3$ & $90,2 \pm 6,1$ & $97,9 \pm 4,7$ & $92,3 \pm 4,5$ \\
\hline \multicolumn{6}{|c|}{$\operatorname{VCL}(\mu \mathrm{m} / \mathrm{s})$} \\
\hline CONT & $124,5 \pm 4,7$ & $125,7 \pm 13,4$ & $133,7 \pm 13,8$ & $124,7 \pm 9,7$ & $127,1 \pm 8,6$ \\
\hline $\mathrm{OP}$ & $137,3 \pm 4,3$ & $112,5 \pm 13,1$ & $117,6 \pm 13,3$ & $144,7 \pm 9,7$ & $128,0 \pm 8,4$ \\
\hline \multicolumn{6}{|c|}{ VSL $(\mu \mathrm{m} / \mathbf{s})$} \\
\hline CONT & $78,0 \pm 4,5$ & $87,2 \pm 7,3$ & $90,2 \pm 5,2$ & $85,6 \pm 4,6$ & $85,3 \pm 4,7$ \\
\hline OP & $82,3 \pm 4,1$ & $81,9 \pm 7,0$ & $82,8 \pm 5,1$ & $86,8 \pm 4,6$ & $83,5 \pm 4,4$ \\
\hline \multicolumn{6}{|c|}{$\mathbf{A L H}(\mu \mathrm{m})$} \\
\hline CONT & $4,8 \pm 0,2$ & $4,3 \pm 0,2$ & $4,6 \pm 0,2$ & $4,3 \pm 0,2$ & $4,5 \pm 0,2$ \\
\hline $\mathrm{OP}$ & $5,0 \pm 0,2$ & $4,6 \pm 0,2$ & $4,5 \pm 0,2$ & $5,0 \pm 0,2$ & $4,8 \pm 0,2$ \\
\hline \multicolumn{6}{|c|}{ BCF (Hz) } \\
\hline CONT & $28,8 \pm 1,8^{\mathrm{Ab}}$ & $30,4 \pm 2,1^{\mathrm{Ab}}$ & $34,4 \pm 1,8^{\mathrm{Aa}}$ & $31,9 \pm 0,7^{\mathrm{Bab}}$ & $31,4 \pm 1,3$ \\
\hline OP & $30,4 \pm 1,6^{\mathrm{Ab}}$ & $28,9 \pm 2,1^{\mathrm{Ab}}$ & $29,4 \pm 1,8^{\mathrm{Ab}}$ & $33,9 \pm 0,7^{\mathrm{Aa}}$ & $30,6 \pm 1,3$ \\
\hline \multicolumn{6}{|l|}{ STR (\%) } \\
\hline CONT & $89,6 \pm 1,1^{\mathrm{Ab}}$ & $92,3 \pm 1,0^{\mathrm{Aa}}$ & $90,7 \pm 1,0^{\text {Aab }}$ & $92,2 \pm 1,0^{\mathrm{Aa}}$ & $91,2 \pm 0,6$ \\
\hline $\mathrm{OP}$ & $88,6 \pm 0,9^{\mathrm{Ab}}$ & $92,2 \pm 1,0^{\mathrm{Aa}}$ & $90,5 \pm 0,9^{\text {Aab }}$ & $89,1 \pm 0,9^{\mathrm{Bb}}$ & $90,1 \pm 0,6$ \\
\hline \multicolumn{6}{|l|}{ LIN (\%) } \\
\hline CONT & $63,7 \pm 1,8^{\mathrm{Ab}}$ & $71,6 \pm 3,2^{\mathrm{Aac}}$ & $68,5 \pm 0,8^{\mathrm{Aa}}$ & $70,3 \pm 1,3^{\mathrm{Ac}}$ & $68,5 \pm 1,3$ \\
\hline OP & $62,4 \pm 1,6^{\mathrm{Ab}}$ & $67,6 \pm 3,3^{\mathrm{Aab}}$ & $67,7 \pm 0,8^{\mathrm{Aa}}$ & $63,8 \pm 1,3^{\mathrm{Bb}}$ & $65,4 \pm 1,3$ \\
\hline
\end{tabular}

Valores com letras minúsculas diferentes sobrescritas na mesma linha diferem significativamente (a-c, $\mathrm{P} \leq 0,05)$. Valores com letras maiúsculas diferentes sobrescritas na mesma coluna diferem significativamente $(\mathrm{A}-\mathrm{B}, \mathrm{P} \leq 0,05)$. CONT: grupo controle; $\mathrm{OP}$ : grupo suplementado com óleo de palma (2\%MS); VAP: velocidade média do trajeto; VCL: velocidade curvilinear; VSL: velocidade linear progressiva; ALH: amplitude de deslocamento lateral da cabeça; BCF: frequência do batimento flagelar cruzado; STR: retilinearidade; LIN: linearidade.

Fonte: Elaboração dos autores.

Houve diferença numérica, com valores superiores nas médias totais para o grupo CONT em todos os parâmetros de cinética espermática, com exceção de VCL e ALH. A variável BCF foi superior para OP no Período IV $(\mathrm{P}<0,05)$, enquanto, no mesmo período, houve elevação de STR e LIN para o grupo CONT $(\mathrm{P}<0,04$ e $\mathrm{P}<0,006$, respectivamente). Quando considerado o efeito do tempo dentro de cada grupo, o CONT apresentou maior média de BCF no Período III $(\mathrm{P}<0,02)$ e o grupo OP mostrou maior média no Período IV $(\mathrm{P}<0,006)$. Ainda considerando o efeito do tempo dentro de cada grupo, a variável STR apresentou aumento significativo no Período II, tanto para o grupo CONT como OP $(\mathrm{P}<0,01$ e $\mathrm{P}<0,03$, respectivamente), com manutenção de valores mais 
altos no CONT até o final do experimento. Já a LIN do grupo CONT apresentou as maiores médias nos Períodos II a IV $(\mathrm{P}<0,02)$, enquanto no grupo OP esse fenômeno ocorreu no Período III $(\mathrm{P}<0,001)$.

\section{Avaliação da morfologia espermática}

A análise da morfologia espermática não revelou diferenças significativas $(\mathrm{P}>0,05)$ entre as médias totais dos grupos CONT e OP para defeitos maiores, menores e totais (Tabela 4).
Os defeitos mais frequentes dentro das categorias foram: defeitos de acrossomo (ACR), gota protoplasmática proximal (GPP), cauda fortemente dobrada ou enrolada (CFD-E), cabeça delgada (CAB-D) e cauda dobrada ou enrolada (CD-E). Foi observado maior nível de células com caudas fortemente dobradas ou enroladas nos touros do grupo OP no Período I $(\mathrm{P}<0,03)$.

Tabela 4. Média de mínimos quadrados \pm erro padrão da morfologia espermática de sêmen bubalino descongelado, avaliada em microscopia de contraste de fase.

\begin{tabular}{|c|c|c|c|c|c|}
\hline \multirow[b]{2}{*}{ Variável } & \multicolumn{4}{|c|}{ Período } & \multirow[b]{2}{*}{ Média Total } \\
\hline & $\begin{array}{c}\mathrm{I} \\
\text { (D0-D30) }\end{array}$ & $\begin{array}{c}\text { II } \\
\text { (D31-D60) }\end{array}$ & $\begin{array}{c}\text { III } \\
\text { (D61-D90) }\end{array}$ & $\begin{array}{c}\text { IV } \\
\text { (D91-D120) }\end{array}$ & \\
\hline \multicolumn{6}{|c|}{ DEF-MA (\%) } \\
\hline CONT & $10,3 \pm 3,9$ & $15,6 \pm 3,7$ & $18,7 \pm 3,7$ & $13,2 \pm 3,7$ & $14,4 \pm 3,1$ \\
\hline $\mathrm{OP}$ & $17,1 \pm 3,5$ & $13,4 \pm 3,8$ & $15,5 \pm 3,6$ & $21,1 \pm 3,6$ & $16,8 \pm 2,9$ \\
\hline \multicolumn{6}{|c|}{$\operatorname{ACR}(\%)$} \\
\hline CONT & $1,1 \pm 0,3$ & $0,7 \pm 0,2$ & $1,2 \pm 0,2$ & $1,4 \pm 0,2$ & $1,1 \pm 0,1$ \\
\hline OP & $1,7 \pm 0,3$ & $1,6 \pm 0,2$ & $0,5 \pm 0,2$ & $1,3 \pm 0,2$ & $1,3 \pm 0,1$ \\
\hline \multicolumn{6}{|c|}{ GPP (\%) } \\
\hline CONT & $1,3 \pm 0,6$ & $1,0 \pm 0,5$ & $1,9 \pm 0,5$ & $1,5 \pm 0,5$ & $1,4 \pm 0,3$ \\
\hline $\mathrm{OP}$ & $1,3 \pm 0,5$ & $1,3 \pm 0,6$ & $2,3 \pm 0,5$ & $1,0 \pm 0,5$ & $1,5 \pm 0,3$ \\
\hline \multicolumn{6}{|c|}{ CFD-E (\%) } \\
\hline CONT & $8,1 \pm 2,9^{\mathrm{Ba}}$ & $11,6 \pm 3,7^{\text {Аа }}$ & $12,7 \pm 4,1^{\mathrm{Aa}}$ & $7,8 \pm 5,6^{\mathrm{Aa}}$ & $10,1 \pm 3,5$ \\
\hline OP & $11,9 \pm 2,6^{\mathrm{Aa}}$ & $8,4 \pm 3,8^{\mathrm{Aa}}$ & $9,7 \pm 4,1^{\mathrm{Aa}}$ & $19,8 \pm 5,3^{\mathrm{Aa}}$ & $12,5 \pm 3,3$ \\
\hline \multicolumn{6}{|c|}{ DEF-ME (\%) } \\
\hline CONT & $3,4 \pm 3,7$ & $5,8 \pm 1,0$ & $7,6 \pm 0,9$ & $5,7 \pm 0,5$ & $5,6 \pm 1,1$ \\
\hline OP & $10,1 \pm 3,4$ & $9,9 \pm 1,0$ & $8,3 \pm 0,9$ & $7,3 \pm 0,5$ & $8,9 \pm 1,1$ \\
\hline \multicolumn{6}{|c|}{ CAB-D (\%) } \\
\hline CONT & $1,6 \pm 0,5$ & $1,4 \pm 0,5$ & $1,2 \pm 0,5$ & $1,4 \pm 0,5$ & $1,4 \pm 0,3$ \\
\hline OP & $1,3 \pm 0,5$ & $1,3 \pm 0,5$ & $2,9 \pm 0,5$ & $1,2 \pm 0,5$ & $1,7 \pm 0,3$ \\
\hline \multicolumn{6}{|c|}{ CD-E (\%) } \\
\hline CONT & $1,6 \pm 2,7$ & $2,2 \pm 1,5$ & $2,5 \pm 0,7$ & $1,9 \pm 0,4$ & $2,0 \pm 0,8$ \\
\hline OP & $7,6 \pm 2,5$ & $3,3 \pm 1,6$ & $2,8 \pm 0,7$ & $3,8 \pm 0,4$ & $4,4 \pm 0,7$ \\
\hline \multicolumn{6}{|c|}{ DEF-T (\%) } \\
\hline CONT & $17,2 \pm 4,2$ & $21,3 \pm 3,9$ & $26,3 \pm 3,9$ & $18,9 \pm 3,9$ & $20,9 \pm 3,2$ \\
\hline $\mathrm{OP}$ & $28,7 \pm 3,8$ & $23,1 \pm 4,1$ & $23,5 \pm 3,8$ & $28,1 \pm 3,8$ & $25,8 \pm 3,0$ \\
\hline
\end{tabular}

Valores com letras minúsculas diferentes sobrescritas na mesma linha diferem significativamente (a-c, $\mathrm{P} \leq 0,05)$. Valores com letras maiúsculas diferentes sobrescritas na mesma coluna diferem significativamente $(\mathrm{A}-\mathrm{B}, \mathrm{P} \leq 0,05)$. CONT: grupo controle; $\mathrm{OP}$ : grupo suplementado com óleo de palma (2\%MS); DEF-MA: defeitos maiores; ACR: defeito de acrossoma; GPP: gota protoplasmática proximal; CFD-E: cauda fortemente dobrada ou enrolada; DEF-ME: defeitos menores; CAB-D: cabeça delgada; CD-E: cauda enrolada; DEF-T: defeitos totais.

Fonte: Elaboração dos autores. 
Avaliação da integridade de membrana plasmática

As porcentagens de espermatozoides com membrana plasmática íntegra, obtidas por meio de diferentes técnicas, estão indicadas a seguir (Tabela $5)$.

Não foram detectadas diferenças significativas entre os grupos CONT e OP. Também, não houve diferença quando foram usados o teste hiposmótico e a coloração por eosina-nigrosina $(\mathrm{P}>0,05)$. Contudo, quando a avaliação por sondas fluorescentes foi aplicada, houve efeito significativo do tempo para os animais do grupo OP, com declínio dos valores no Período III e retorno aos valores originais no Período IV $(\mathrm{P}<0,003)$.

Tabela 5. Média de mínimos quadrados \pm erro padrão da integridade de membrana plasmática de espermatozoides em sêmen bubalino descongelado, avaliada por meio de três diferentes técnicas.

\begin{tabular}{|c|c|c|c|c|c|}
\hline \multirow[b]{2}{*}{ Testes } & \multicolumn{4}{|c|}{ Período } & \multirow[b]{2}{*}{ Média Total } \\
\hline & $\begin{array}{c}\mathrm{I} \\
\text { (D0-D30) }\end{array}$ & $\begin{array}{c}\text { II } \\
\text { (D31-D60) }\end{array}$ & $\begin{array}{c}\text { III } \\
\text { (D61-D90) }\end{array}$ & $\begin{array}{c}\text { IV } \\
\text { (D91-D120) }\end{array}$ & \\
\hline \multicolumn{6}{|c|}{ HOST (\%) } \\
\hline CONT & $29,2 \pm 3,5$ & $30,7 \pm 3,1$ & $32,4 \pm 3,1$ & $41,9 \pm 3,1$ & $33,6 \pm 1,6$ \\
\hline OP & $35,3 \pm 3,1$ & $33,8 \pm 3,5$ & $29,1 \pm 3,1$ & $36,7 \pm 3,1$ & $33,7 \pm 1,6$ \\
\hline \multicolumn{6}{|c|}{ E-N (\%) } \\
\hline CONT & $35,0 \pm 3,8$ & $33,8 \pm 3,4$ & $37,1 \pm 3,4$ & $40,9 \pm 3,4$ & $36,7 \pm 1,7$ \\
\hline $\mathrm{OP}$ & $43,2 \pm 3,4$ & $34,6 \pm 3,8$ & $36,4 \pm 3,4$ & $46,3 \pm 3,4$ & $40,1 \pm 1,7$ \\
\hline \multicolumn{6}{|c|}{ IP-H342 (\%) } \\
\hline CONT & $36,7 \pm 4,8$ & $43,5 \pm 3,9$ & $41,9 \pm 5,7$ & $41,1 \pm 2,5$ & $40,8 \pm 3,4$ \\
\hline $\mathrm{OP}$ & $41,8 \pm 4,3^{\mathrm{ab}}$ & $32,7 \pm 4,0^{\mathrm{bc}}$ & $29,0 \pm 5,5^{c}$ & $46,7 \pm 2,5^{\mathrm{a}}$ & $37,5 \pm 3,2$ \\
\hline
\end{tabular}

Valores com letras minúsculas diferentes sobrescritas na mesma linha diferem significativamente (a-c, $\mathrm{P} \leq 0,05)$. Valores com letras maiúsculas diferentes sobrescritas na mesma coluna diferem significativamente $(\mathrm{A}-\mathrm{B}, \mathrm{P} \leq 0,05)$. CONT: grupo controle; $\mathrm{OP}$ : grupo suplementado com óleo de palma (2\%MS); HOST: teste hiposmótico; E-N: teste com coloração de eosina-nigrosina; IP-H342: teste com coloração fluorescente com associação de iodeto de propídio e Hoescht 33342.

Fonte: Elaboração dos autores.

Equivalência entre as técnicas de avaliação da integridade de membrana plasmática

Os resultados do coeficiente de correlação, da equação linear da reta estimada e do coeficiente de determinação para verificar a equivalência entre as técnicas de avaliação da integridade da membrana plasmática são apresentados na Tabela 6.

Verificou-se, nesta análise, uma baixa relação entre as técnicas de E-N em função de HOST e de HOST em função de IP-H342 com coeficientes de correlação de 34 e $36 \%$, respectivamente. A equivalência mais expressiva entre as técnicas foi para IP-H342 em função de E-N que revelou um alto grau de relacionamento linear evidenciado pelo coeficiente de correlação de $91 \%$. No modelo de regressão, para explicar a relação linear $(\mathrm{Y}=\mathrm{a}+\mathrm{bX})$ entre estas duas técnicas, considerou-se IP-H342 como variável dependente (Y) e E-N como variável independente $(\mathrm{X})$. A equação da reta ajustada explicou, pelo coeficiente de determinação, $82 \%$ da variabilidade total dos dados.

Na Figura 1 tem-se o gráfico de dispersão para os dados das técnicas de coloração com sondas fluorescentes (IP-H342) versus os dados da técnica de eosina-nigrosina (E-N) e a equação da reta ajustada por regressão linear sobre os pontos.

A análise revelou uma alta associação $(\mathrm{R}=91 \%)$, seguindo um comportamento linear $(\mathrm{Y}=2,98+$ $0,92 \mathrm{X})$, com alto coeficiente de determinação $\left(\mathrm{R}^{2}=0,82\right)$. 
Tabela 6. Relação entre as técnicas de sondas fluorescentes (IP-H342) e coloração de eosina-nigrosina (E-N) para avaliação da integridade de membrana plasmática de espermatozoides bubalinos.

\begin{tabular}{ccccc}
\hline Relação & Correlação (R) & Equação & $\mathrm{R}^{2}$ & P-valor \\
\hline IP-H342 e E-N & $91 \%$ & $\mathrm{Y}=2,98+0,92 \mathrm{X}$ & 0,82 & $<0,0001$ \\
\hline
\end{tabular}

Fonte: Elaboração dos autores.

Figura 1. Gráfico de dispersão dos dados de avaliação da integridade de membrana plasmática de espermatozoides bubalinos, obtidos por meio das técnicas com sondas fluorescentes iodeto de propídio/Hoechst 33342 (IP-H342) e com eosina-nigrosina (E-N).

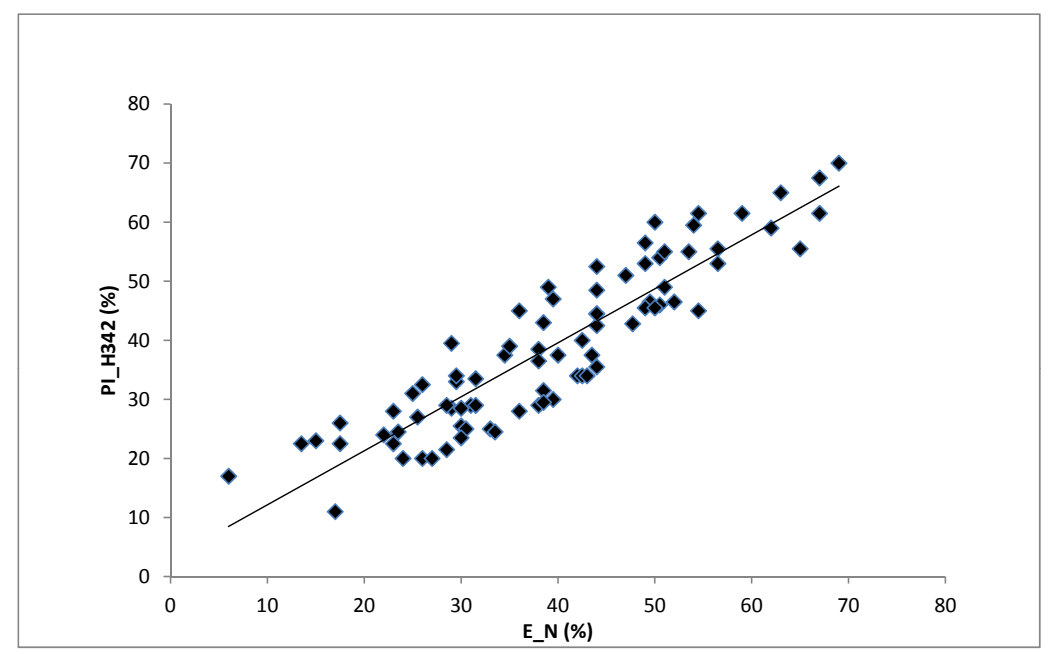

Fonte: Elaboração dos autores.

\section{Discussão}

No presente estudo, foi avaliado se a suplementação de touros bubalinos com ácidos graxos insaturados na dieta, utilizando como fonte o óleo de palma a $2 \%$ da matéria seca total, poderia alterar as características do sêmen descongelado. Não existem relatos na literatura para a espécie bubalina sobre o efeito da suplementação com UFAs na dieta sobre a motilidade e cinética espermáticas avaliadas pelo CASA e sobre a integridade de membrana espermática avaliada com sondas fluorescentes. Há relato semelhante para búfalos, realizado com suplementação com óleo e semente de girassol na dieta, tendo como parâmetros de resposta os efeitos sobre a motilidade subjetiva e a integridade de membrana plasmática avaliada em teste hiposmótico (ADEEL et al., 2009).

A motilidade progressiva subjetiva póscriopreservação encontrada para o grupo CONT
$(36,9 \pm 2,7)$ e para o grupo OP $(35,5 \pm 2,7 \%)$ é superior a dados publicados para touros búfalos mantidos em central de inseminação artificial, que foi de 26,7\% (ALEXIEV et al., 1994). Independentemente do método de avaliação adotado (microscopia óptica ou CASA), houve discreta influência da dieta nos parâmetros de motilidade espermática após a descongelação. Resultados semelhantes de motilidade espermática foram obtidos após a descongelação de sêmen ovino, não sendo observadas alterações nesses parâmetros após a adição dos ácidos oleico e linoleico na dieta, durante seis semanas (GRAAF et al., 2007). O mesmo aconteceu com suínos suplementados com ácidos graxos poli-insaturados ( $\omega-3)$ provenientes do óleo de peixe, não havendo efeito dos lipídios sobre as características de motilidade total $(\mathrm{P}>0,177)$ e integridade das membranas biológicas após a descongelação do sêmen (CASTELLANO et al., 2010). Em contrapartida, estudo realizado com 
touros bubalinos alimentados com óleo de girassol ou com semente de girassol a $1 \%$ da matéria seca total da dieta, durante 63 dias, mostrou que após a descongelação do sêmen houve aumento significativo $(\mathrm{P}<0,05)$ da motilidade total para os animais que receberam UFAs na dieta (ADEEL et al., 2009).

Para as variáveis que designam a cinética dos espermatozoides, houve influência da suplementação lipídica após o processo descongelação em três parâmetros $(\mathrm{BCF}, \mathrm{STR}$ e LIN), os quais indicam, em conjunto, a habilidade de progressão dos espermatozoides em um determinado trajeto (CONTRI et al., 2010). O BCF, que já foi apontado como sendo correspondente ao vigor das células espermáticas (CONTRI et al., 2010), foi positivamente influenciado pela suplementação com ácidos graxos insaturados, com diferença entre grupos notada a partir de 90 dias do início da suplementação, ou seja, a partir da segunda espermatogênese completa sob efeito da dieta, uma vez que para o touro bubalino um ciclo espermatogênico completo e o tempo de armazenamento no epidídimo levam, em média, 48 dias (FRANÇA; AVELAR; ALMEIDA, 2005).

Estudo prévio mostra que o ácido docosahexaenoico desempenha um papel importante na fluidez da membrana plasmática e está envolvido na maior flexão flagelar dos espermatozoides e, por conseguinte, na maior frequência nos batimentos (SELVARAJU et al., 2012). Espermatozoides de bovinos e bubalinos apresentam grande quantidade de ácidos graxos poli-insaturados na cauda (AHLUWALIA; HOLMAN, 1969; KADIRVEL et al., 2009), o que pode contribuir para elevar a atividade flagelar espermática, devido ao maior aporte de fosfolipídios, que podem ser utilizados como fonte de energia para a fosforilação oxidativa nas mitocôndrias e que podem conferir maior proteção à membrana mitocondrial durante a criopreservação e descongelação (PIOMBONI et al., 2011). No presente estudo, não foi analisado o perfil de ácidos graxos na membrana plasmática dos espermatozoides. No entanto, supõe-se que o aumento do BCF para os animais tratados indica a possibilidade de haver maior incorporação de UFAs na membrana espermática e, por isso, ter havido aumento da intensidade dos batimentos, como reportado para bovinos (GHOLAMI et al., 2010). Altos valores de BCF estão associados à maior atividade mitocondrial (RASUL; AHMAD; ANZAR, 2001), além de maior capacidade de migração e penetração do espermatozoide no muco cervical (VERSTEGEN; IGUER-OUADA; ONCLIN, 2002), aumentando as chances de fertilização do oócito (MORTIMER, 2000).

A retilinearidade (STR, \%) estima a proximidade do percurso da célula a uma linha reta, calculada pela razão VSL/VAP. Já a linearidade (LIN, \%) é dada pela relação VSL/VCL, e determina que quanto mais o espermatozoide se afasta da velocidade em linha reta, menor será o valor de LIN (VERSTEGEN; IGUEROUADA; ONCLIN, 2002). No presente estudo, tanto STR como LIN apresentaram comportamento inverso ao $\mathrm{BCF}$, sendo que as maiores médias foram observadas para o grupo CONT no último período. Este comportamento pode estar associado aos resultados de morfologia espermática, visto que, no último período experimental os animais do grupo OP apresentaram valores de caudas fortemente dobradas ou fortemente enroladas numericamente superiores ao grupo CONT $(\mathrm{P}>0,05)$, o que pode ter influenciado na trajetória linear das células.

Apesar da linearidade dos espermatozoides do grupo OP ter diminuído no Período IV, os níveis obtidos $(63,7 \%)$ são semelhantes aos níveis mais adequados de linearidade para fertilização (COX et al., 2002), pois estudos realizados com sêmen caprino demonstram que espermatozoides com valor médio para LIN de $60 \pm 1,3 \%$ foram capazes de percorrer maiores distâncias no muco cervical in vitro $(\mathrm{P}<0,05)$ quando comparados aos ejaculados que possuíam $66,6 \pm 1,0 \%$ e $58 \pm 1,4 \%$ de linearidade no movimento espermático (COX et al., 2006).

Sabe-se que a viscosidade do meio interfere na livre circulação dos espermatozoides pelo plasma 
seminal (CASTELLINI et al., 2000). Estudos recentes indicam que búfalos submetidos à dieta rica em lipídios apresentaram elevação das taxas séricas de lipídios totais e de colesterol (SILVA et al., 2014), e que sob essas circunstâncias o plasma seminal pode incorporar maior quantidade de colesterol livre (GLIOZZI et al., 2009). Em tese, esses fatores são capazes de aumentar a viscosidade do plasma seminal e alterar a trajetória em linha reta da célula espermática. Sendo assim, a diminuição de STR e LIN no último período para os touros do grupo OP pode também estar relacionada possivelmente à mudança da viscosidade do plasma seminal, o qual não é removido previamente à criopreservação do sêmen, na espécie bubalina.

Em relação à morfologia dos espermatozoides após a descongelação, houve incremento no grupo OP no número de células com cauda fortemente dobrada ou enrolada, no primeiro período $(8,1 \pm 2,9$ versus $11,9 \pm 2,6 ; \mathrm{P}<0,05)$. Essa diferença notada tem pouca relevância prática, pois o incremento foi de pequena magnitude, não perdurou nos Períodos II a IV, e não impactou nas médias gerais dos tratamentos. A porcentagem de espermatozoides totais com morfologia anormal em ambos os grupos esteve aquém de $30 \%$, valor estabelecido como referência para sêmen de touros bubalinos usados em programas de inseminação artificial (CBRA, 2013). Esses valores são próximos dos $20 \%$ de defeitos espermáticos totais observados no sêmen in natura de búfalos, quando suplementados com uso de UFAS (SILVA et al., 2014), o que sugere que a suplementação lipídica pode exercer efeito protetor em ejaculados que devam passar pelo processo de criopreservação. O uso de lipídios na dieta presumivelmente não incrementou a deposição de gordura peritesticular, sendo um fator que influenciaria na termorregulação testicular (GHOLAMI et al., 2010) e poderia determinar marcante elevação na quantidade de patologias de cauda no ejaculado, o que ocorre quando a temperatura testicular está acima de $32^{\circ} \mathrm{C}$ em búfalos (OHASHI et al., 1988).
Não houve diferença nos níveis de integridade de membrana plasmática avaliados pelas técnicas de HOST e eosina-nigrosina, corroborando resultados encontrados para sêmen bovino descongelado, proveniente de touros alimentados com dietas enriquecidas com ácidos graxos poli-insaturados (GHOLAMI et al., 2010). Quando caprinos foram alimentados com óleo de peixe, não foi encontrada diferença significativa para integridade de membrana plasmática, avaliada pelo teste de coloração com eosina-nigrosina (DOLATPANAH et al., 2008). Contudo, há relato de que a porcentagem de espermatozoides com membrana plasmática íntegra mensurada pelo HOST foi superior no sêmen descongelado, quando búfalos foram alimentados com óleo ou semente de girassol (ADEEL et al., 2009).

Quando a associação de iodeto de propídio e Hoescht 33342 foi utilizada, percebeu-se efeito no grupo OP $(\mathrm{P}<0,05)$, sendo possível constatar oscilações nos Períodos II e III, e maior quantidade de células com membranas íntegras no último período. Esses dados concordam com estudo em suínos alimentados com dieta rica em ácido docosahexaenoico, os quais apresentaram maiores médias de espermatozoides com membrana plasmática íntegra, quando comparados ao grupo controle (KAEOKET et al., 2010). Distintamente, a associação das sondas fluorescentes SYBR-14/ iodeto de propídio não detectou diferenças na integridade de membrana plasmática em sêmen de suínos alimentados com diferentes fontes de lipídios na dieta (CASTELLANO et al., 2010).

Para avaliar as alterações na membrana plasmática dos espermatozoides, várias técnicas laboratoriais são empregadas e correlacionadas com o objetivo de buscar a que melhor indica a integridade da membrana (LARSSON; RODRIGUEZ-MARTINEZ, 2000). Neste estudo, foi observada alta relação entre as técnicas de coloração com as sondas fluorescentes iodeto de propídio/Hoescht 33342 e eosina-nigrosina. Os resultados permitiram calcular uma equação (IP- 
$\mathrm{H} 342=2,98+0,92 * \mathrm{E}-\mathrm{N})$ com alto coeficiente de determinação $\left(R^{2}=0,82\right)$. Assim, pode-se predizer com certa segurança, através do valor da técnica com coloração de eosina-nigrosina (E-N), como o resultado da análise se comportaria se fossem empregadas sondas fluorescentes (IP-H342). Os resultados corroboram informações de estudos realizados com sêmen bovino descongelado, nos quais foi constatada maior correlação entre eosinanigrosina e sondas fluorescentes, no caso o diacetato de 6-carboxifluoresceína associado ao iodeto de propídio (BRITO et al., 2003; ZÚCCARI et al., 2009).

A coloração de eosina-nigrosina possui alta habilidade em diferenciar células com membrana plasmática lesada após a descongelação, assim como o corante fluorescente de iodeto de propídio (PINTADO; DE LA FUENTE; ROLDAN, 2000). É provável que a semelhança entre os mecanismos de ação dos corantes favoreceu a associação matemática das técnicas. O corante eosina atravessa a membrana plasmática danificada corando o citoplasma em rosa (FOSTER et al., 2011). Da mesma forma, o iodeto de propídio ultrapassa a membrana plasmática lesada, ligando-se, porém, ao DNA e emitindo fluorescência em vermelho. Já a sonda Hoescht 33342 atravessa a membrana intacta e se liga ao DNA, emitindo fluorescência azul (CELEGHINI et al., 2007).

Apesar dos corantes fluorescentes serem considerados os mais específicos indicadores do status molecular da célula, a técnica de eosinanigrosina apresenta algumas vantagens, por ter menor custo, requerer equipamentos menos sofisticados, ser mais rápida e poder ser executada a campo. Ainda, o teste com eosina-nigrosina está altamente associado à capacidade espermática para formação de pronúcleos durante o processo de fecundação e a porcentagem de espermatozoides classificados como tendo membrana plasmática íntegra por essa técnica se relaciona a níveis mais elevados de sucesso na fertilização in vitro (TANGHE et al., 2002).

\section{Conclusões}

A inclusão de ácidos graxos poli-insaturados oriundos do óleo de palma na dieta, a 2\% da matéria seca total, não influenciou na motilidade espermática, mas foi capaz de mostrar efeitos positivos na habilidade de progressão das células espermáticas após 90 dias do início da suplementação, estando esta característica relacionada ao aumento do potencial de fertilidade do sêmen após a descongelação. A suplementação não demonstrou exercer efeito negativo na morfologia nem na integridade da membrana plasmática dos espermatozoides. Entre as três técnicas analíticas usadas para avaliação de membranas, a coloração de eosina-nigrosina pode ser utilizada como preditora dos níveis de integridade de membrana plasmática, de forma segura e eficiente, quando as condições para execução da técnica com sondas fluorescentes de iodeto de propídio e Hoescht 33342 não sejam existentes.

\section{Agradecimentos}

Às equipes do Laboratório de Medidas Físicas (UFPA), da Fábrica de Rações (UFRA) e do Laboratório de Biotecnologia do Sêmen e Andrologia (FMVZ/USP) pelo apoio na execução do trabalho. À Embrapa (Rede BIOTEC, códigos 0107010204 e 0107010203$)$, CAPES e CNPq pelo suporte financeiro e bolsas de estudo.

\section{Referências}

ADEEL, M.; IJAZ, A.; ALEEM, M.; REHMAN, H.; YOUSAF, M. S.; JABBAR, M. A. Improvement of liquid and frozen-thawed semen quality of Nili-Ravi buffalo bulls (Bubalus bubalis) through supplementation of fat. Theriogenology, Philadelphia, v. 71, n. 8, p. 1220$1225,2009$.

AHLUWALIA, B.; HOLMAN, R. T. Fatty acid composition of lipid of bull, boar, rabbit and human semen. Journal of Reproduction and Fertility, London, v. 18, n. 3, p. 431-437, 1969. 
ALEXIEV, A.; KOLEV, S.; DANEV, A. D.; STOJANOVA, M. Characteristics of buffalo bulls sperm production in Bulgaria. In: WORLD BUFFALO CONGRESS, 4., 1994, São Paulo. Proceedings... São Paulo: Brazilian Buffalo Breeders Association, 1994. p. 492-494.

AM-IN, N.; KIRKWOOD, R. N.; TECHAKUMPHU, M.; TANTASUPARUK, W. Lipid profiles of sperm and seminal plasma from boars having normal or low sperm motility. Theriogenology, Philadelphia, v. 75, n. 5, p. 897-903, 2011.

ANDRABI, S. M. H. Factors affecting the quality of cryopreserved Buffalo (Bubalus bubalis) bull spermatozoa. Reproduction in Domestic Animals, Malden, v. 44, n. 3, p. 552-569, 2009.

ANIL KUMAR, R.; SUNDARARAMAN, M. N.; PATEL, D. V.; IYUE, M.; KASIRAJ, R. Cryopreservation of semen as a venture for conservation of wild and endangered Toda Buffalo germplasm. Buffalo Bulletin, Wyoming, v. 30, n. 3, p. 210-218, 2011.

ARRUDA, R. P.; CELEGHINI, E. C. C.; SOUZA, L. W. O.; NASCIMENTO, J.; ANDRADE, A. F. C.; RAPHAEL, C. F.; GARCIA, A.R. Importance of semen quality in fixed-time artificial insemination and embryo transfer programs. Acta Scientiae Veterinariae, Porto Alegre, v. 33, p. 145-150, 2005. Supplement 1.

BARROS, P. M. H.; NICHI, M.; CORTADO, C. N. M.; CARVALHO, N. A. T.; BARUSELLI, P. S.; BARNABE, R. C.; BARNABE, V. H. Semen evaluation of Murrah buffalo bulls using sperm functional tests. Italian Journal of Animal Science, Pavia, v. 6, n. 2, p. 772-774, 2007.

BLOM, E. Ultrastructure of some characteristic sperm defects and a proposal for a new classification of the bull spermiogram. Nordisk Veterinaer-Medicin, Copenhagen, v. 25, n. 7 , p. 383-391, 1973.

BORGHESE, A.; MAZZI, M. Buffalo population and strategies in the world. In: BORGHESE, A. (Ed.). Buffalo population and research. Rome: FAO, 2005. p. 1-39.

BRITO, L. F. C.; BARTH, A. D.; BILODEAUGOESEELS, S.; PANICHI, P. L.; KASTELIC, J. P. Comparison of methods to evaluate the plasmalemma of bovine sperm and their relationship with in vitro fertilization rate. Theriogenology, Philadelphia, v. 60, n. 8, p. 1539-1551, 2003.

CASTELlANO, C. A.; AUDET, I.; BAILEY, J. L.; LAFOREST, J. P.; MATTE, J. J. Dietary omega-3 fatty acids (fish oils) have limited effects on boar semen stored at $17^{\circ} \mathrm{C}$ or cryopreserved. Theriogenology, Philadelphia, v. 74, n. 8, p. 1482-1490, 2010.
CASTELlinI, C.; LATTAIOLI, P.; MORONI, M.; MINELLI, A. Effect of seminal plasma on the characteristics and fertility of rabbit spermatozoa. Animal Reproduction Science, Manchester, v. 63, n. 3, p. 275-282, 2000.

CASTRO, S. R. S. Uso de antioxidantes para elevação da qualidade do sêmen criopreservado de Búfalos (Bubalus bubalis). 2010. Dissertação (Mestrado em Ciência Animal) - Universidade Federal do Pará, Belém.

CELEGHINI, E. C. C.; ARRUDA, R. P.; ANDRADE, A. F. C.; NASCIMENTO, J.; RAPHAEL, C. F. Practical techniques for bovine sperm simultaneous fluorimetric assessment of plasma, acrossomal and mitochondrial membranes. Reproduction in Domestic Animals, Malden, v. 42, n. 2, p. 479-488, 2007.

COLÉGIO BRASILEIRO DE REPRODUÇÃO ANIMAL - CBRA. Manual para exame andrológico e avaliação de sêmen animal. 3. ed. Belo Horizonte: CBRA, 2013, 104 p.

CONTRI, A.; GLORIA, A.; ROBBE, D.; VALORZ, C.; WEGHER, L.; CARLUCCIO, A. Kinematic study on the effect of $\mathrm{pH}$ on bull sperm function. Animal Reproduction Science, Manchester, v. 136, n. 4, p. 252-259, 2013.

CONTRI, A.; VALORZ, C.; FAUSTINI, M.; WEGHER, L.; CARLUCCIO, A. Effect of semen preparation on casa motility results in cryopreserved bull spermatozoa. Theriogenology, Philadelphia, v. 74, n. 3, p. 424-435, 2010 .

COX, J. F.; ALFARO, V.; MONTENEGRO, F.; RODRIGUEZ-MARTINEZ, H. Computer-assisted analysis of sperm motion in goats and its relationship with sperm migration in cervical mucus. Theriogenology, Philadelphia, v. 66, n. 4, p. 860-867, 2006.

COX, J. F.; ZAVALA, A.; SARAVIA, F.; RIVAS, C.; GALLARDO, P.; ALFARO, V. Differences in sperm migration through cervical mucus in vitro relates to sperm colonization of the oviduct and fertilizing ability in goats. Theriogenology, Philadelphia, v. 58, n. 1, p. 9-18, 2002.

DOLATPANAH, M. B.; TOWHIDI, A.; FARSHAD, A.; RASHIDI, A.; REZAYAZDI, A. Effects of dietary fish oil on semen quality of goats. Asian-Australasian Journal of Animal Sciences, Gwanak-gu, v. 21, n. 1, p. 29-34, 2008.

FERGUSON, E. M.; LEESE, H. J. A potential role for triglyceride as an energy source during bovine oocyte maturation and early embryo development. Molecular Reproduction Development, Malden, v. 73, n. 9, p. 11951201, 2006. 
FOSTER, M. L.; LOVE, C. C.; VARNER, D. D.; BRINSKO, S. P.; HINRICHS, K.; TEAGUE, S.; LACAZE, K.; BLANCHARD, T. L. Comparison of methods for assessing integrity of equine sperm membranes. Theriogenology, Philadelphia, v. 76, n. 2, p. 334-341, 2011.

FRANÇA, L. R.; AVELAR, G. F.; ALMEIDA, F. F. L. Spermatogenesis and sperm transit through the epididymis in mammals with emphasis on pigs. Theriogenology, Philadelphia, v. 63, n. 2, p. 300-318, 2005.

FREITAS, A. R.; SOUZA, J. F.; MOREIRA, A. Predição da precocidade sexual em bovinos da raça Nelore por meio de componentes principais. Revista de Ciências Agrárias, Belém, v. 54, n. 2, p. 153-158, 2011.

GARCIA, A. R.; NAHÚM, B. S.; LOURENÇO JUNIOR, J. B.; COSTA, N. A.; GONÇALVES, K. S.; MIYASAKI, M. Y. A.; ANDRADE, A. F. C.; ARRUDA, R. P. Associação de medroxiprogesterona ao protocolo Ovsynch para inseminação artificial em tempo fixo de búfalas cíclicas (Bubalus bubalis) criadas na Amazônia Oriental. Acta Amazonica, Manaus, v. 38, n. 3, p. 369378, 2008 .

GHOLAMI, H.; CHAMANI, M.; TOWHIDI, A.; FAZELI, M. H. Effect of feeding a docosahexaenoic acid-enriched nutriceutical on the quality of fresh and frozen-thawed semen in Holstein bulls. Theriogenology, Philadelphia, v. 74, n. 9, p. 1548-1558, 2010.

Improvement of semen quality in Holstein bulls during heat stress by dietary supplementation of Omega-3 fatty acids. International Journal of Fertility \& Sterility, Tehran, v. 4, n. 4, p. 160-167, 2011.

GLIOZZI, T. M.; ZANIBONI, L.; MALDJIAN, A.; LUZI, F.; MAERTENS, L.; CEROLINI, S. Quality and lipid composition of spermatozoa in rabbits fed DHA and vitamin E rich diets. Theriogenology, Philadelphia, v. 71, n. 6, p. 910-919, 2009.

GRAAF, S. P.; PEAKE, K.; MAXWELL, W. M.; O'BRIEN, J. K.; EVANS, G. Influence of supplementing diet with oleic and linoleic acid on the freezing ability and sex-sorting parameters of ram semen. Livestock Science, Amsterdam, v. 110, n. 1, p. 166-173, 2007.

HOLT, W. V. Basic aspects of frozen storage of semen. Animal Reproduction Science, Manchester, v. 62, n. 1, p. 3-22, 2000.

HUSSAIN, S. A.; LESSARD, C.; ANZAR, M. A strategy for improvement of post thaw quality of bison sperm. Theriogenology, Philadelphia, v. 79, n. 1, p. 108-115, 2013.
KADIRVEL, G.; KUMAR, S.; KUMARESAN, A.; KATHIRAVAN, P. Capacitation status of fresh and frozen-thawed buffalo spermatozoa in relation to cholesterol level, membrane fluidity and intracellular calcium. Animal Reproduction Science, Manchester, v. 116, n. 3-4, p. 244-253, 2009.

KAEOKET, K.; SANG-URAI, P.; THAMNIYOM, A.; CHANAPIWAT, P.; TECHAKUMPHU, M. Effect of docosahexaenoic acid on quality of cryopreserved boar semen in different breeds. Reproduction in Domestic Animals, Malden, v. 45, n. 3, p. 458-463, 2010.

KHAN, M. I. R.; IJAZ, A. Effect of osmotic pressure on motility, plasma membrane integrity and viability in fresh and frozen-thawed buffalo spermatozoa. Animal, Cambridge, v. 2, n. 4, p. 548-553, 2008.

KOONJAENAK, $\quad$ S.; $\quad$ PONGPENG, P.; WIROJWUTHIKUL, S.; JOHANNISSON, A.; KUNAVONGKRIT, A.; RODRIGUEZ-MARTINEZ, H. Seasonality affects post-thaw plasma membrane intactness and sperm velocities in spermatozoa from Thai AI swamp buffaloes (Bubalus bubalis). Theriogenology, Philadelphia, v. 67, n. 9, p. 1424-1435, 2007.

KUMAR, R.; ATREJA, S. K. Effect of incorporation of additives in Tris- based egg yolk extender on buffalo (Bubalus bubalis) sperm tyrosine phosphorylation during cryopreservation. Reproduction in Domestic Animals, Malden, v. 47, p. 485-490, 2012.

KUMAR, S.; SAHNI, K. L.; BENJAMIN, B. N.; MOHAN, G. Effect of various levels of yolk on deep freezing and storage of buffalo semen in different diluters without adding glycerol. Journal of Buffalo Science, Mississauga, v. 1, p. 79-85, 1993.

LARSSON, B.; RODRIGUEZ-MARTINEZ, H. Can we use in vitro fertilization tests to predict semen fertility. Animal Reproduction Science, Manchester, v. 60-61, n. 1-2, p. 327-336, 2000.

LENZI, A.; PICARDO, M.; GANDINI, L.; DONDERO, F. Lipids of the sperm plasma membrane: from polyunsaturated fatty acids considered as markers of sperm function to possible scavenger therapy. Human Reproduction Update, Cambridgeshire, v. 2, n. 3, p. 246256, 1996.

LOURENÇO JÚNIOR, J. B.; GARCIA, A. R. Produção animal no bioma amazônico: atualidades e perspectivas. Revista Brasileira de Zootecnia, Viçosa, MG, v. 35, p. 63-83, 2006. Suplemento Especial.

MANDAL, D. K.; BAGPAUL, P. K.; GUPTA, A. K. Motion characteristics of Murrah buffalo bull spermatozoa in various seasons and its relationship with functional integrity of the plasmallema. Theriogenology, Philadelphia, v. 60, n. 2, p. 349-358, 2003. 
MAZIERO, R. R. D.; CRESPILHO, A. M.; FREITASDELL'AQUA, C. P.; DELL'AQUA JUNIOR, J. A.; PAPA, F. O. Análise de sêmen bovino e sua relação com a fertilidade. Revista Brasileira de Reprodução Animal, Belo Horizonte, v. 33, n. 4, p. 5-10, 2009.

MELO, M. I. V.; HENRY, M. Teste hiposmótico na avaliação de sêmen eqüino. Arquivo Brasileiro de Medicina Veterinária e Zootecnia, Belo Horizonte, v. 51, n. 6, p. 71-78, 1999.

MORTIMER, S. T. CASA - Practical aspects. Journal of Andrology, Hoboken, v. 21, n. 4, p. 515-524, 2000.

NORHAIZAN, M. E.; HOSSEINI, S.; GANGADARAN, S.; LEE, S. T.; KAPOURCHALI, F. R.; MOGHADASIAN, M. H. Palm oil: features and applications. Lipid Technology, Weinheim, v. 25, n. 2, p. 39-42, 2013.

OHASHI, O. M.; SOUSA, J.; RIBEIRO, H. F. L.; VALE, W. G. Distúrbios reprodutivos em touros Bos indicus, Bos taurus e mestiços, criados em clima amazônico. Pesquisa Veterinária Brasileira, Seropédica, v. 8, n. 1-2, p. 31-35, 1988.

PAUL, S. S.; LAL, D. Nutrient requirements of buffaloes. Azadpur, Delhi: Satish Serial Publishing House, 2010. $138 \mathrm{p}$.

PINTADO, B.; DE LA FUENTE, J.; ROLDAN, E. R. S. Permeability of boar and bull spermatozoa to the nucleic acid stains propidium iodide or Hoescht 33258 , or to eosin: accuracy in the assessment of cell viability. Journal of Reproduction \& Fertility, Tehran, v. 118, n. 1, p. 145-152, 2000.

PIOMBONI, P.; FOCARELLI, R.; STENDARDI, A.; FERRAMOSCA, A.; ZARA, V. The role of mitochondria in energy production for human sperm motility. International Journal of Andrology, Malden, v. 35, n. 2, p. 109-124, 2011.

RASUL, Z.; AHMAD, N.;ANZAR, M. Antagonist effects of DMSO on the cryoprotection ability of glycerol during cryopreservation of buffalo sperm. Theriogenology, Philadelphia, v. 68, n. 5, p. 813-819, 2007.

Changes in motion characteristic, plasma membrane integrity, and acrosome morphology during cryopreservation of buffalo spermatozoa. Journal of Andrology, Hoboken, v. 22, n. 2, p. 278-283, 2001.

Effect of buffering systems on post-thaw motion characteristic, plasma membrane integrity, and acrosome morphology of buffalo spermatozoa. Animal Reproduction Science, Manchester, v. 59, n. 1-2, p. 3141, 2000.
ROBINSON, J. J.; ASHWORTH, C. J.; ROOKE, J. A.; MITCHELL, L. M.; MCEVOY, T. G. Nutrition and fertility in ruminant livestock. Animal Feed Science and Technology, Amsterdam, v. 126, n. 3-4, p. 259-276, 2006.

RODRIGUES, A. M. C.; DARNET, S.; SILVA, L. H. M. Fatty acid profiles and tocopherol contents of buriti (Mauritia flexuosa), patawa (Oenocarpus bataua), tucuma (Astrocaryum vulgare), mari (Poraqueiba paraensis) and inaja (Maximiliana maripa) fruits. Journal of the Brazilian Chemical Society, Campinas, v. 21, n. 10, p. 2000-2004, 2010.

SANSONE, G.; NASTRI, M. J.; FABBROCINI, A. Storage of buffalo (Bubalus bubalis) semen. Animal Reproduction Science, Manchester, v. 62, n. 1-3, p. 5576, 2000.

STATISTICAL ANALISYS SYSTEM INSTITUTE SAS. User's guide. Version 9.1.3 for Windows. Cary, NC: USA, 2003.

SELVARAJU, S.; GHOSH, J.; RAVINDRA, J. P. Prognostic value of various spermatological attributes as predictors of zona binding and zona penetration of buffalo (Bubalus bubalis) semen. Reproduction in Domestic Animals, Malden, v. 44, n. 1, p. 6-11, 2009.

SELVARAJU, S.; RAJU, P.; RAO, S. B.; RAGHAVENDRA, S.; NANDI, S.; DINESHKUMAR, D.; THAYAKUMAR, A.; PARTHIPAN, S.; RAVINDRA, J. P. Evaluation of maize grain and polyunsaturated fatty acid (PUFA) as energy sources for breeding rams based on hormonal, sperm functional parameters and fertility. Reproduction, Fertility and Development, Collingwood, v. 24, n. 5, p. 669-678, 2012.

SILVA, G. R.; GARCIA, A. R.; FATURI, C.; LOURENÇO JUNIOR, J. B.; NAHÚM, B. S.; GONÇALVES, A. A.; KAWHAGE, P. R.; SILVA, L. H. M.; MENESES, A. M. C. Adição de óleo de palma na dieta sobre a lipidemia e a qualidade do sêmen de bubalinos (Bubalus bubalis). Arquivo Brasileiro de Medicina Veterinária e Zootecnia, Belo Horizonte, v. 66, n. 1, p. 152-160, 2014.

TANGHE, S.; VAN SOOM, A.; STERCKY, V.; MAES, D.; KRUIF, A. Assessment of different sperm quality parameter to predict in vitro fertility of bulls. Reproduction in Domestic Animals, Malden, v. 37, n. 3, p. 127-132, 2002.

VALE, W. G. Reproductive management of buffalo male aiming semen production for artificial insemination. In: BUFFALO SYMPOSIUM OF AMERICAS, 1., 2002, Belém. Proceedings... Belém: PRODEPA/Governo do Estado do Pará, 2002. p. 156-171. 
VALE, W. G.; RIBEIRO, H. F. L.; SOUSA, J. S.; OHASHI, O. M. Inseminação artificial em búfalos (Bubalus bubalis) na região Amazônica. In: CONGRESSO BRASILEIRO DE MEDICINA VETERINÁRIA, 19., 1984, Belém. Proceedings... Brasília: Sociedade Brasileira de Medicina Veterinária, 1984. p. 91.

VERSTEGEN, J.; IGUER-OUADA, M.; ONCLIN, K. Computer assisted semen analyzers in andrology research and veterinary practice. Theriogenology, Philadelphia, v. 57, n. 1, p. 149-179, 2002.

WANG, X. J.; DYSON, M. T.; JO, Y.; EUBANK, D. $\mathrm{W}$;; STOCCO, D. M. Involvement of 5-lipoxygenase metabolites of arachidonic acid in cyclic AMP-stimulated steroidogenesis and steroidogenic acute regulatory protein gene expression. Journal of Steroid Biochemistry and Molecular Biology, Philadelphia, v. 85, n. 2-5, p. 159-166, 2003.
WATHES, D. C.; ABAYASEKARA, D. R. E.; AITKEN, R. J. Polyunsaturated fatty acids in males and female reproduction. Biology of Reproduction, Madison, v. 77, n. 2, p. 190-201, 2007.

WATSON, P. F. The cause of reduce fertility with cryopreserved semen. Animal Reproduction Science, Manchester, v. 60-61, p. 481-492, 2000.

YÁNIZ, J. L.; PALACIN, I.; VICENTE-FIEL, S.; GOSALVEZ, J.; LÓPEZ-FERNÁNDEZ, C.; SANTOLARI, P. Comparison of membrane-permeant fluorescent probes for sperm viability assessment in the Ram. Reproduction in Domestic Animals, Malden, v. 48, n. 4, p. 1-6, 2012.

ZÚCCARI, C. E. S. N.; LEITE, P. A.; PASSOS, T. S.; CARRIJO, P. R.; KIEFER, C. Correlação entre métodos de avaliação da integridade da membrana plasmática do espermatozoide bovino criopreservado. Revista Brasileira de Saúde e Produção Animal, Salvador, v. 10, n. 3, p. 678-684, 2009 . 